\section{New endoscopic ultrasonography techniques for pancreaticobiliary diseases}

\author{
Ken Kamata, Masayuki Kitano, Shunsuke Omoto, Kumpei Kadosaka, Takeshi Miyata, \\ Kosuke Minaga, Kentaro Yamao, Hajime Imai, Masatoshi Kudo
}

Department of Gastroenterology and Hepatology, Kinki University Faculty of Medicine, Osaka-Sayama, Japan

Endoscopic ultrasonography (EUS) is widely used to evaluate pancreaticobiliary diseases, especially pancreatic masses. EUS has a good ability to detect pancreatic masses, but it is not sufficient for the differential diagnosis of various types of lesions. In order to address the limitations of EUS, new techniques have been developed to improve the characterization of the lesions detected by EUS. EUS-guided fine needle aspiration (EUS-FNA) has been used for diagnosing pancreatic tumors. In order to improve the histological diagnostic yield, a EUS-FNA needle with a core trap has recently been developed. Contrast-enhanced harmonic EUS is a new imaging modality that uses an ultrasonographic contrast agent to visualize blood flow in fine vessels. This technique is useful in the diagnosis of pancreatic solid lesions and in confirming the presence of vascularity in mural nodules for cystic lesions. EUS elastography analyzes several different variables to measure tissue elasticity, color patterns, and strain ratio, using analytical techniques such as hue-histogram analysis, and artificial neural networks, which are useful for the diagnosis of chronic pancreatitis and pancreatic cancer.

Keywords: Endosonography; Endoscopic ultrasound-guided fine needle aspiration;

Elasticity imaging techniques; Biliary tract; Pancreas; Sonazoid

\section{Introduction}

Endoscopic ultrasonography (EUS) is widely used to evaluate pancreaticobiliary diseases, especially pancreatic masses [1-5]. EUS has an adequate ability to detect pancreatic masses, but it is not sufficient for the differential diagnosis of various types of lesions. A recently published report has shown that when pancreatic carcinoma was defined as a hypoechoic lesion, the sensitivity and specificity of conventional EUS were $86 \%$ and $18 \%$, respectively [6]. In order to overcome the limitations of EUS, new techniques, such as contrast-enhanced EUS, EUS elastography (EUS-E), and EUS-guided fine needle aspiration (EUS-FNA) have been developed to characterize the lesions detected by EUS.

\section{EUS-FNA}

\section{Solid Lesions of the Pancreas}

EUS-FNA was developed for the pathological diagnosis of lesions in and adjacent to the digestive

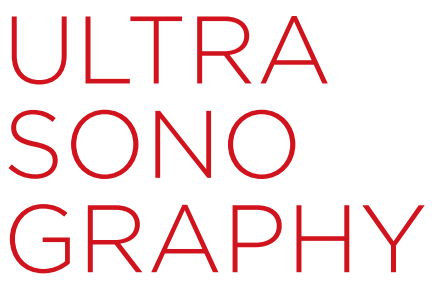

\section{REVIEW ARTICLE}

http://dx.doi.org/10.14366/usg. 15042 pISSN: 2288-5919 e elSSN: 2288-5943

Ultrasonography 2015;35:169-179

Received: July 27, 2015

Revised: April 10, 2016

Accepted:April 12, 2016

Correspondence to:

Masayuki Kitano, MD, PhD, Department of Gastroenterology and Hepatology, Kinki University Faculty of Medicine, 377-2 Ohno-Higashi, OsakaSayama 589-8511, Japan

Tel. +81-72-366-0221 (ext. 3525)

Fax. +81-72-367-2880

E-mail: m-kitano@med.kindai.ac.jp

This is an Open Access article distributed under the terms of the Creative Commons Attribution NonCommercial License (http://creativecommons.org/ licenses/by-nc/3.0/) which permits unrestricted noncommercial use, distribution, and reproduction in any medium, provided the original work is properly cited.

Copyright @ 2016 Korean Society of Ultrasound in Medicine (KSUM)

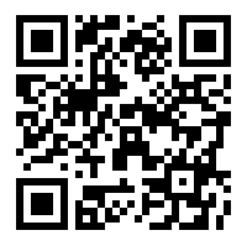

How to cite this article:

Kamata K, Kitano M, Omoto S, Kadosaka K, Miyata T, Minaga K, et al. New endoscopic ultrasonography techniques for pancreaticobiliary diseases. Ultrasonography. 2016 Jul;35(3):169-179. 
tract and has a diagnostic accuracy of $60 \%$ to $90 \%$, depending on the site that is investigated [7]. EUS-FNA is particularly useful for diagnosing pancreatic tumors and assists in making treatment decisions. For these carcinomas, it has a diagnostic sensitivity of $54 \%-96 \%$, a specificity of $96 \%-98 \%$, and an accuracy of $83 \%-95 \%$ [8-11]. Various EUS-FNA needles have been developed, including 25-, 22-, and 19-gauge needles. Of particular note, 25-gauge needles are easier to handle and cause fewer complications. Several studies have shown that, in comparison to 22- and 19-gauge needles, 25-gauge needles are more maneuverable and are less likely to yield samples contaminated with blood [12-15]. Additionally, the lesions are more easily penetrated. Moreover, a recently published prospective comparative study showed that 25-gauge FNA needles had a better diagnostic yield in solid pancreatic tumors than 22-gauge FNA needles (pooled sensitivity: $93 \%$ for 25 -gauge needles vs. $85 \%$ for 22 -gauge needles) [16]. However, this finding only applied to cytology-based diagnoses, as the 25-gauge needle was inferior to the 22-gauge needle in terms of the accuracy of histology-based diagnoses. In order to improve the diagnostic yield, a histological diagnosis is needed, especially when immunohistological analysis is required (e.g., when a neuroendocrine tumor or malignant lymphoma is suspected). For this reason, a EUS-FNA needle with a core trap was developed recently (Fig. 1) [17-22]. It provides histological core tissue using a 25-gauge needle, even in a single pass, and several studies have shown it to improve the diagnostic yield in solid pancreatic tumors, particularly in the histological diagnosis. Thus, the selection of an optimal FNA needle depends on the purpose of EUS-FNA. The technique used during EUS-FNA is also important for improving accuracy. The fanning technique, which involves sampling multiple areas within a lesion during each pass, was found to be superior to the standard approach because fewer passes were required to establish the diagnosis [23]. The slow-pull technique is a new technique during EUS-FNA procedures. In this technique, after the mass is punctured, the stylet is slowly pulled out without suction [21]. It was found that the slow-pull technique was associated with less contamination with blood and resulted in a higher diagnostic yield when a smaller (25- or 22-gauge) core biopsy needle was used. This pattern was also observed when slow-pull aspiration with a standard 25-gauge EUS-FNA needle was followed by either histological diagnosis or cytology. Thus, many options are available for EUS-FNA, and further study is required to establish the optimal methods for EUS-FNA.

\section{Cystic Lesions of the Pancreas}

EUS-FNA is efficient for the differential diagnosis of pancreatic cysts. It also identifies the main pancreatic duct communication by measuring intracystic pancreatic enzymes or tumor markers such as amylase, lipase, and carcinoembryonic antigen (CEA) [24-29]. Brugge et al. [24] reported a 79\% accuracy for diagnosing mucinous cystic neoplasms when the cut-off value of CEA was defined as $192 \mathrm{ng} / \mathrm{mL}$. Van der Waaij et al. [25] reported a 98\% specificity for identifying mucinous cystic neoplasms as malignant when CEA in the cyst was $>800 \mathrm{ng} / \mathrm{mL}$ and also indicated that a cyst fluid amylase concentration of $<250 \mathrm{U} / \mathrm{L}$ virtually excluded the possibility of a pseudocyst. Although EUS-FNA rarely causes complications such as hemorrhage $(0.2 \%-6 \%)$ and infection $(0.2 \%-5 \%)$, determining how management may be affected by the imaging information is essential before performing EUS-FNA [26-28]. Cyst size is often the most important determinant of success in cyst aspiration and the acquisition of adequate fluid for analysis. Walsh et al. [29] showed that a minimum cyst size of $1.5 \mathrm{~cm}$ was needed to obtain at least one variable (cytology, CEA, and amylase) with an $84 \%$ success rate, and therefore endorsed using EUS-FNA for pancreatic cysts $1.5 \mathrm{~cm}$ or larger. Recently, through-the-needle imaging has been employed for evaluating pancreatic cysts. Needle-based confocal laser endomicroscopy (nCLE) that can be inserted into 19-gauge EUS-FNA needles has been developed to allow observations to be made within the cyst $[30,31]$. By using $n C L E$, images of the internal structure of the cyst are obtained, which are similar to histopathological images. This novel technique is expected to be of use for the differential diagnosis of malignant versus non-malignant as well as mucinous versus non-mucinous cystic neoplasms.

\section{Gallbladder Masses}

EUS-FNA of gallbladder masses was first reported by Jacobson et al. in 2003 [32]. Although only small case series have been published, the FNA of gallbladder masses has been found to have high sensitivity $(80 \%-100 \%)$ and specificity [33-35]. However, the effectiveness of EUS-FNA for the diagnosis of gallbladder tumors is questionable. It is necessary to consider bile leakage and/or seeding related to FNA, although no reports have described severe complications in EUS-FNA for gallbladder tumors.

\section{Contrast-Enhanced EUS}

Contrast-enhanced EUS includes contrast-enhanced Doppler EUS and contrast-enhanced harmonic EUS (CH-EUS). Contrast-enhanced Doppler remains limited in terms of real-time vessel imaging due to artifacts such as blooming. $\mathrm{CH}$-EUS selectively depicts harmonic components that are integer multiples of the fundamental frequency $[36,37]$. When microbubbles oscillate or are broken after receiving a certain range of acoustic power, harmonic components are produced. The harmonic component derived from microbubbles is higher than that obtained from tissues; thus, contrast harmonic 
imaging depicts signals from the microbubbles with greater intensity than it depicts signals from the tissue by selectively detecting the harmonic components [36,37]. CH-EUS is a new imaging modality

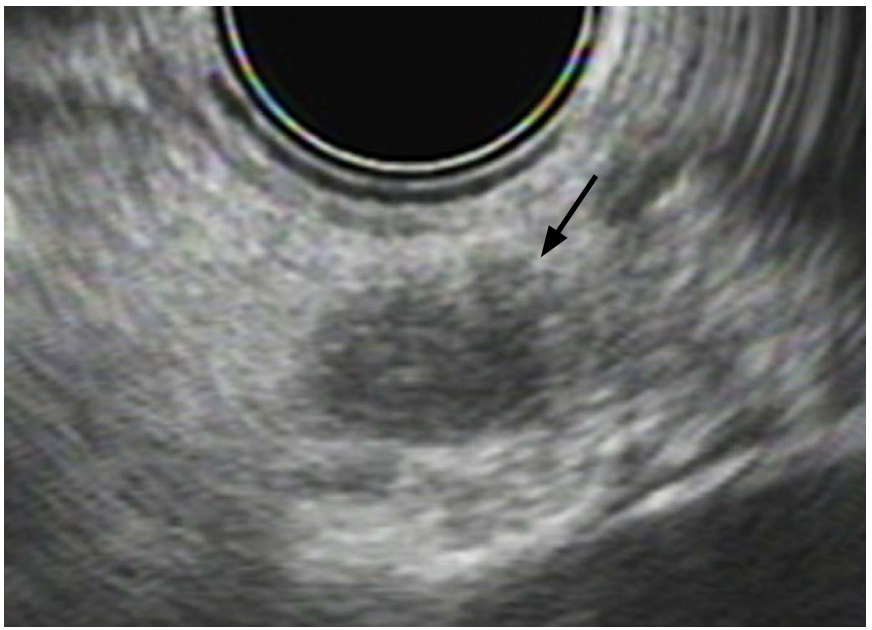

A

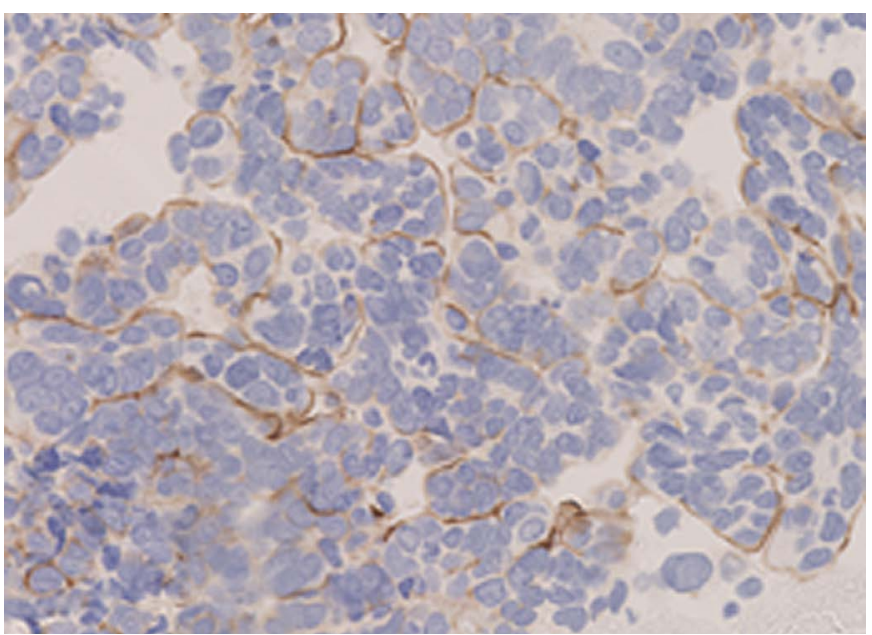

C

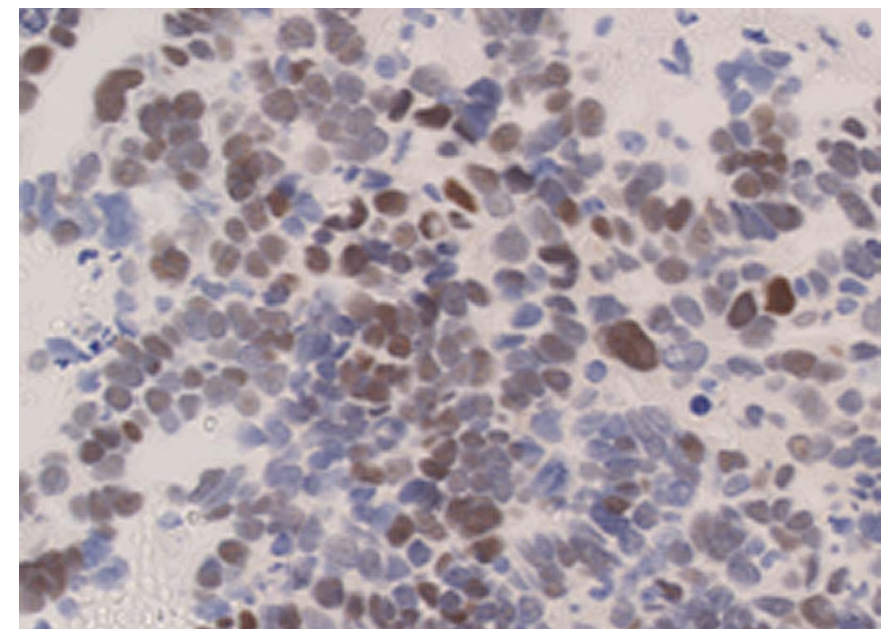

$\mathrm{E}$ that uses an ultrasonographic contrast agent to visualize blood flow in fine vessels.

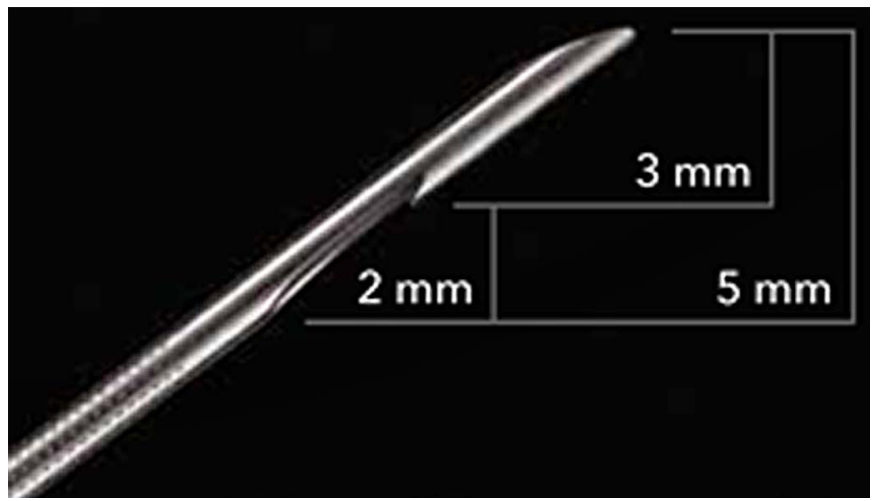

B

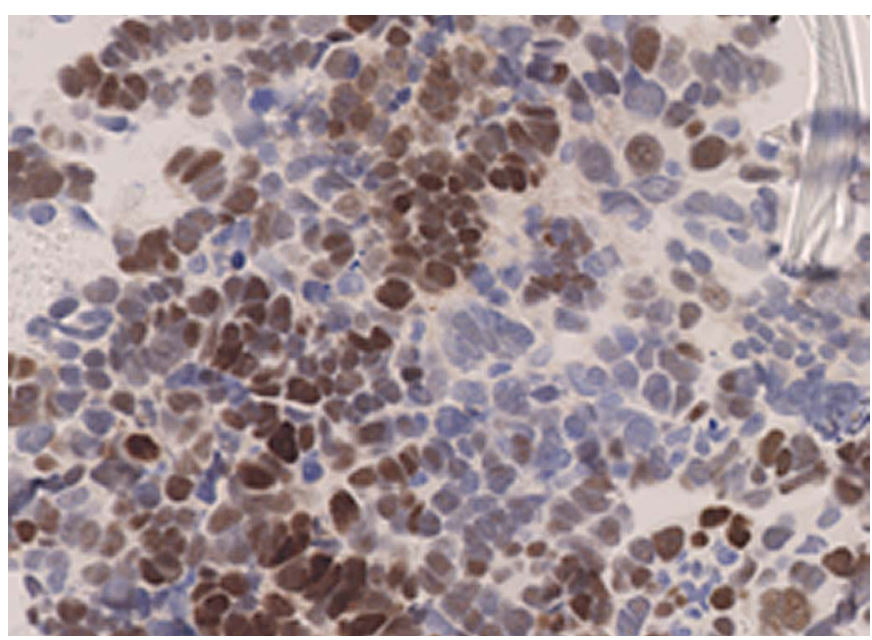

D

Fig. 1. A 50-year-old woman with pancreatic metastasis of ovarian carcinoma as diagnosed by endoscopic ultrasonographyguided fine needle aspiration (EUS-FNA).

A. EUS shows a 12-mm hypoechoic mass (arrow) in the body of the pancreas. B. A 25-gauge needle with a core trap was used for EUS-FNA. The core was located at the top of the needle. C-E. Immunohistochemical studies demonstrate the following results: $C A$ $125(+)(C)$, estrogen receptor $(++)(D)$, and progesterone receptor $(+)(E)(C-E, \times 400)$. 


\section{Solid Lesions of the Pancreas}

On CH-EUS, solid pancreatic lesions can be classified into four patterns depending on the enhancement pattern: non-enhancement, hypoenhancement, isoenhancement, and hyperenhancement [6,3840]. Pancreatic carcinomas possess a certain degree of enhancement, mostly hypoenhancement, whereas benign necrotic tissue does not exhibit enhancement (Fig. 2, Video clip 1). In contrast, most neuroendocrine tumors exhibit hyperenhancement (Fig. 3) [6,3840]. A recently published meta-analysis has shown that when pancreatic adenocarcinomas were diagnosed based on showing hypoenhancement in CH-EUS, the pooled diagnostic sensitivity and specificity were $94 \%$ and $89 \%$, respectively [41]. When CH-EUS was compared to conventional EUS in detecting pancreatic carcinomas, the former (with pancreatic carcinomas defined as hypoenhanced lesions) had better sensitivity and specificity than the latter (96\% vs. $86 \%$ and $64 \%$ vs. $18 \%$, respectively) [6]. Moreover, CH-EUS clearly depicts the outline of ductal carcinomas, even when the conventional EUS finding is uncertain. This could help clarify the location of the target tumor for performing EUS-FNA. CH-EUS and contrast-enhanced computed tomography (CT) are comparable in

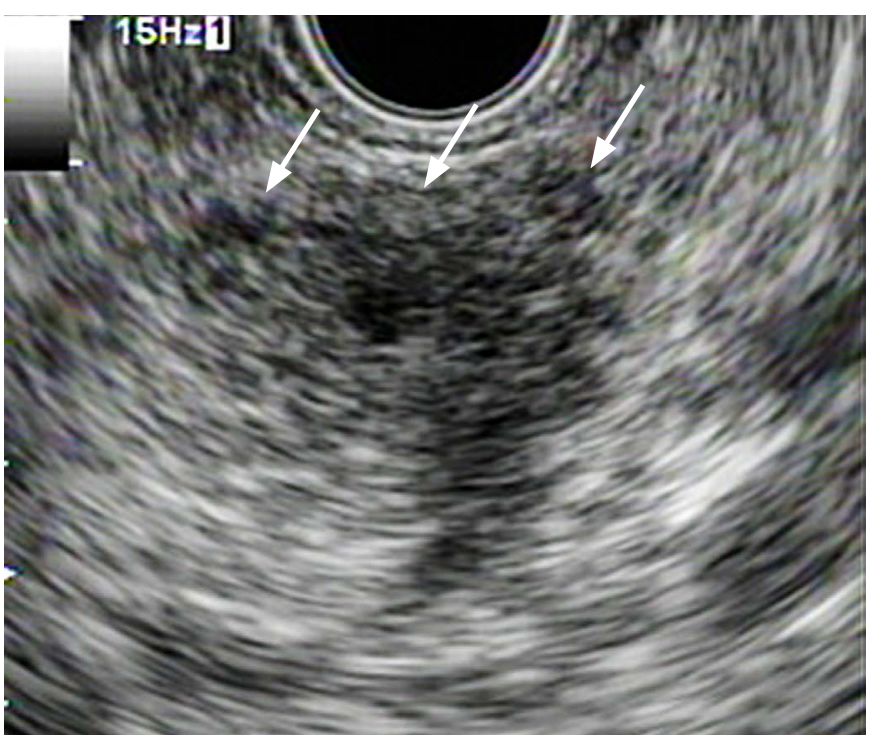

A

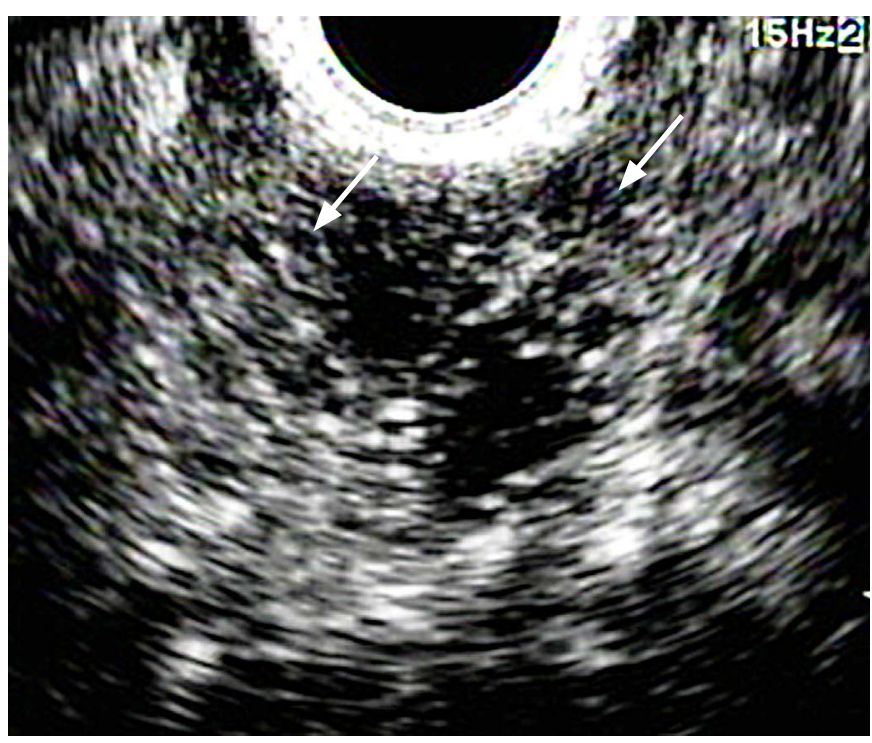

B

Fig. 2. A 67-year-old man with pancreatic ductal adenocarcinoma.

A. Fundamental B-mode endoscopic ultrasonography (EUS) shows a 20-mm hypoechoic tumor (arrows) in the body of the pancreas. B. Contrast-enhanced harmonic EUS shows hypoenhancement of the lesion (arrows).

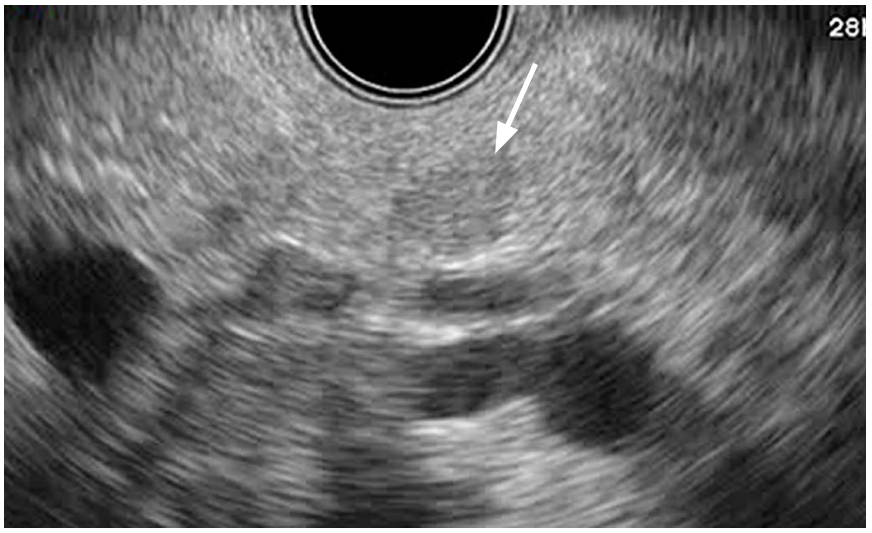

A

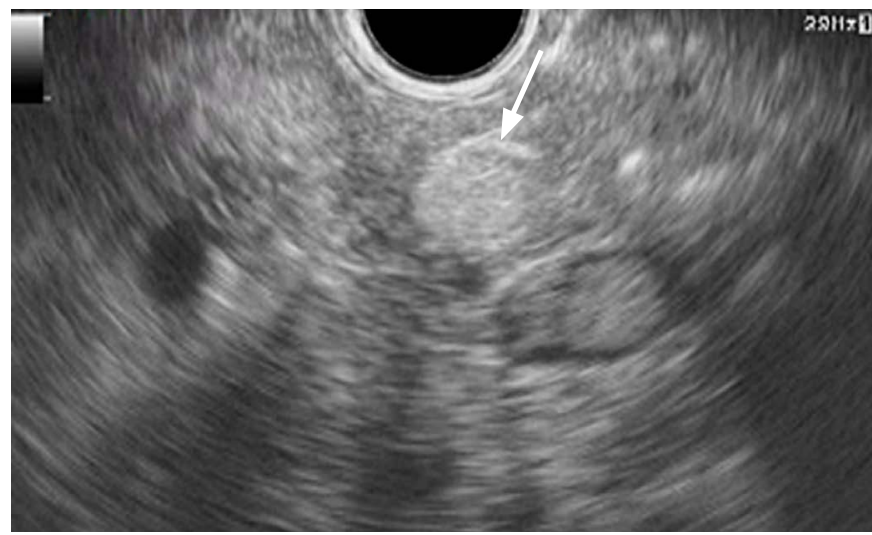

B

Fig. 3. A 42-year-old woman with a neuroendocrine tumor in the pancreas.

A. Fundamental B-mode endoscopic ultrasonography (EUS) shows a 7-mm hypoechoic tumor (arrow) in the body of the pancreas. B. Contrast-enhanced harmonic EUS demonstrates hyperenhancement of the lesion (arrow). 
terms of differentiating pancreatic carcinomas from other masses. However, for small carcinomas $(\leq 2 \mathrm{~cm}), \mathrm{CH}$-EUS was found to be superior (sensitivity, 91\%; specificity, 94\%) in comparison with contrast-enhanced CT (sensitivity, 71\%; specificity, 92\%) [38]. This shows that CH-EUS is useful for characterizing small neoplasms that contrast-enhanced $\mathrm{CT}$ cannot identify. The combination of $\mathrm{CH}$ EUS and EUS-FNA is useful for accurately diagnosing pancreatic cancer. When ductal carcinomas were defined as tumors with hypoenhancement on CH-EUS and/or a positive EUS-FNA result, the sensitivity and specificity were $100 \%$ and $92.6 \%$, respectively [38]. Combining CH-EUS with EUS-FNA increased the sensitivity of EUSFNA from $92.2 \%$ to $100 \%$.

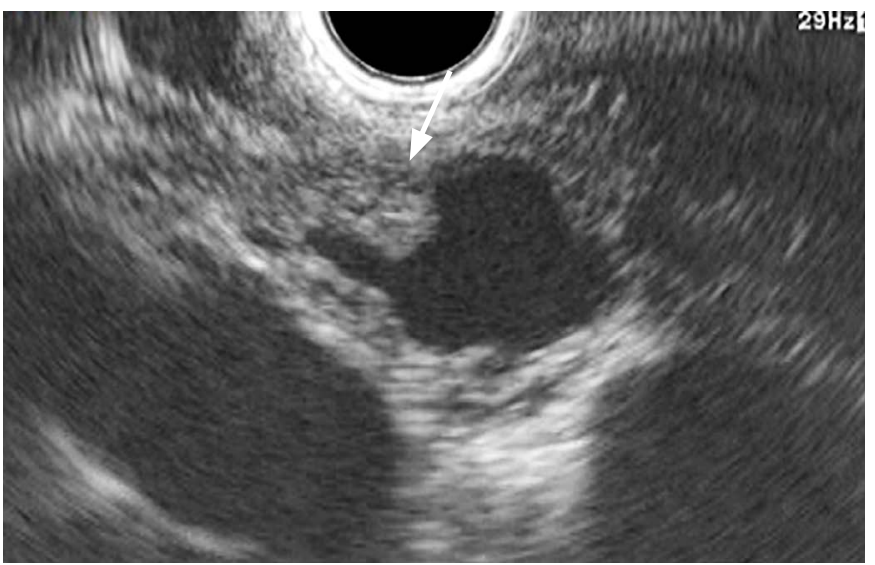

A

Fig. 4. A 72-year-old man with intrapapillary mucinous neoplasms exhibiting high-grade dysplasia.

A. Fundamental B-mode endoscopic ultrasonography (EUS) shows a mural nodule in the cystic lesion (arrow). B. Contrast-enhanced harmonic EUS demonstrates vascularity in the mural nodule (arrow) on contrast-enhanced harmonic EUS.

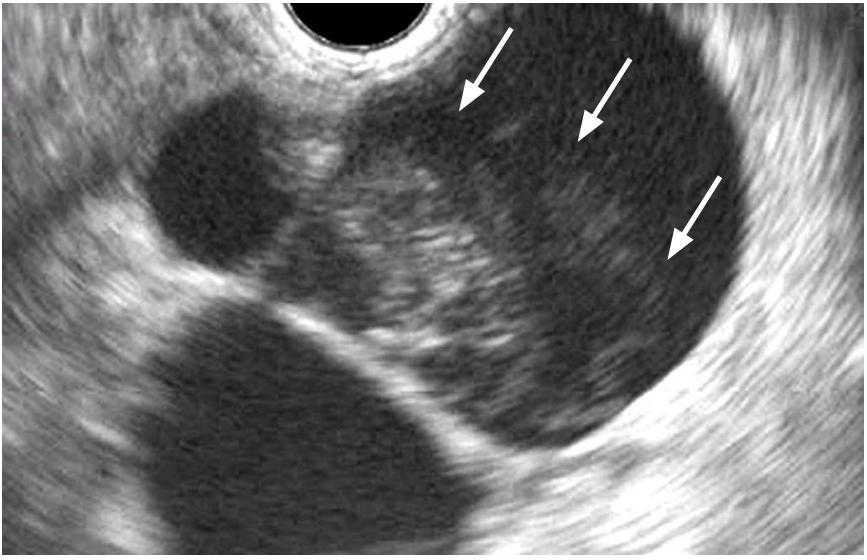

A

\section{Cystic Lesions of the Pancreas}

Internal structural features of cystic tumors, including the locularity, cystic component, appearance, and/or the presence of a thick wall and/or mural nodules are important in the differential diagnosis of cystic lesions of the pancreas $[42,43]$. CH-EUS may also aid in the diagnosis of pancreatic cysts through the assessment of the vascularity of structures such as the cyst wall, septa, or mural nodules, as well as by distinguishing contrast-enhancing mural nodules from non-enhancing mucus clots (Figs. 4, 5, Video clip 2) [37]. It is important to evaluate mural nodules in intraductal papillary mucinous neoplasms in order to perform a differential diagnosis of malignant versus non-malignant. However, standard EUS may misdiagnose mucus clots as mural nodules; therefore, confirming the

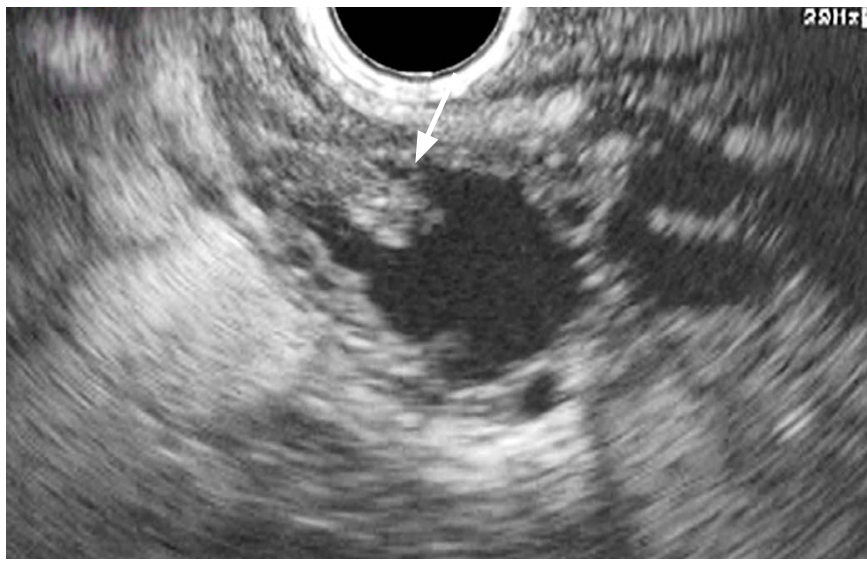

B

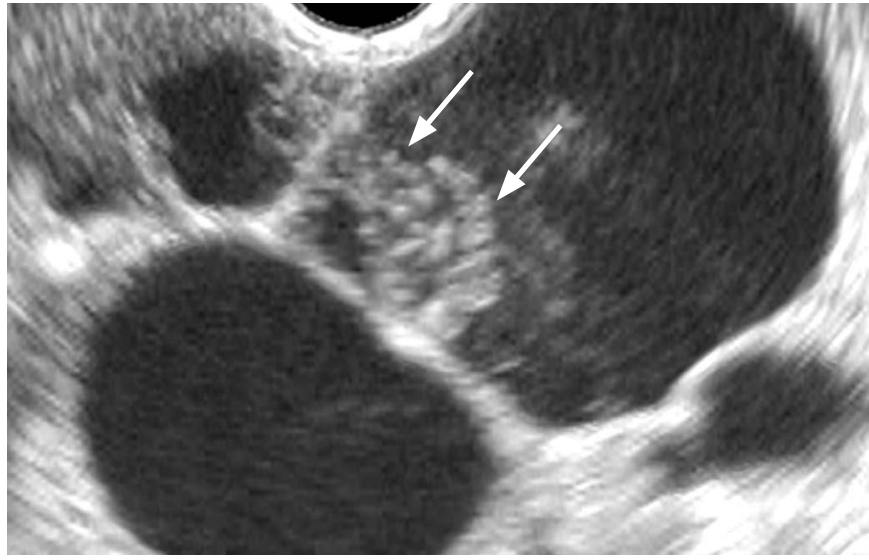

B

Fig. 5. A 74-year-old man with an intraductal papillary mucinous neoplasm exhibiting high-grade dysplasia.

A. Fundamental B-mode endoscopic ultrasonography (EUS) shows suspicious mural nodules in the cystic lesion (arrows). B. Contrastenhanced harmonic EUS shows that a part of the lesion had vascularity (arrows), and it was considered to be a true mural nodule. 
presence of vascularity in the mural nodule on $\mathrm{CH}$-EUS is important and helps to avoid unnecessary surgical resection. Several studies have evaluated the vascular patterns of mural nodules. Ohno et al. [44] classified mural nodules into four groups based on vascularity (low papillary nodules, polypoid nodules, papillary nodules, and invasive nodules) using contrast-enhanced Doppler EUS, and reported that papillary and invasive nodule patterns were associated with malignancy. Kurihara et al. [45] evaluated the vascularity of mural nodules measuring more than $10 \mathrm{~mm}$ using transabdominal ultrasonography and reported that a branch-shaped pattern was associated with carcinoma.

\section{Gallbladder Lesions}

Hirooka et al. [46] first reported the usefulness of CH-EUS using sonicated albumin for the diagnosis of gallbladder lesions in 1998. The authors reported that the accuracy of the determination of tumor invasion for conventional EUS was $78.6 \%$, whereas it was $92.9 \%$ for CH-EUS. Imazu et al. [47] reported that an inhomogeneous enhancement pattern on CH-EUS for wall thickening of the gallbladder indicated malignancy. They evaluated CH-EUS using a Sonazoid and reported that the sensitivity, specificity, accuracy, positive predictive value, negative predictive value, and area under the receiver operating curve (ROC) of CH-EUS were $89.6 \%, 98 \%, 94.4 \%, 97.7 \%, 92.2 \%$, and 0.94 , respectively. These values are superior to those of conventional EUS. With respect to gallbladder polyps, the presence of irregular intratumoral vessels or perfusion defects seen on $\mathrm{CH}$-EUS was a sensitive and accurate predictor of malignant gallbladder polyps [48]. In that study, it was found that in 93 patients with gallbladder polyps larger than $10 \mathrm{~mm}$ in diameter, an irregular vessel pattern determined by CH-EUS aided in the diagnosis of malignant polyps, with a sensitivity and specificity of $90.3 \%$ and $96.6 \%$, respectively. The presence of perfusion defects was able to diagnose malignant polyps with a sensitivity and specificity of $90.3 \%$ and $94.9 \%$, respectively. Thus, malignant gallbladder lesions can be characterized as showing inhomogeneous enhancement and/or irregular vessels on CH-EUS (Fig. 6). In another small series, Park et al. [49] found that CH-EUS also helped differentiate cholesterol polyps from gallbladder adenomas. They studied 87 patients with gallbladder polyps and found that the sensitivity and specificity of $\mathrm{CH}$-EUS for the differential diagnosis of gallbladder adenomas from cholesterol polyps based on the enhancement pattern were $75.0 \%$ and $66.6 \%$, respectively. CH-EUS may be useful for the differential diagnosis of gallbladder lesions, but the clinical efficacy of CH-EUS in deciding on a treatment strategy remains questionable. Moreover, the visual assessment of $\mathrm{CH}$-EUS images is subjective and an additional quantitative analysis is required.

\section{EUS Elastography}

The major principle of tissue elastography is that a compressive force is applied to the tissue, causing axial tissue deformation (strain), which is then calculated by comparing the echo sets before and after the compression [50]. EUS-E is an adjunctive imaging technique that allows the tissue elasticity of a solid mass to be assessed during a conventional EUS examination [51,52]. This technique allows the direct visualization of information reflecting strain superimposed on the fundamental B-mode image as a strain distribution map (the elastogram), which, for visualization purposes, is color-coded and displayed next to the fundamental B-mode image on the screen.

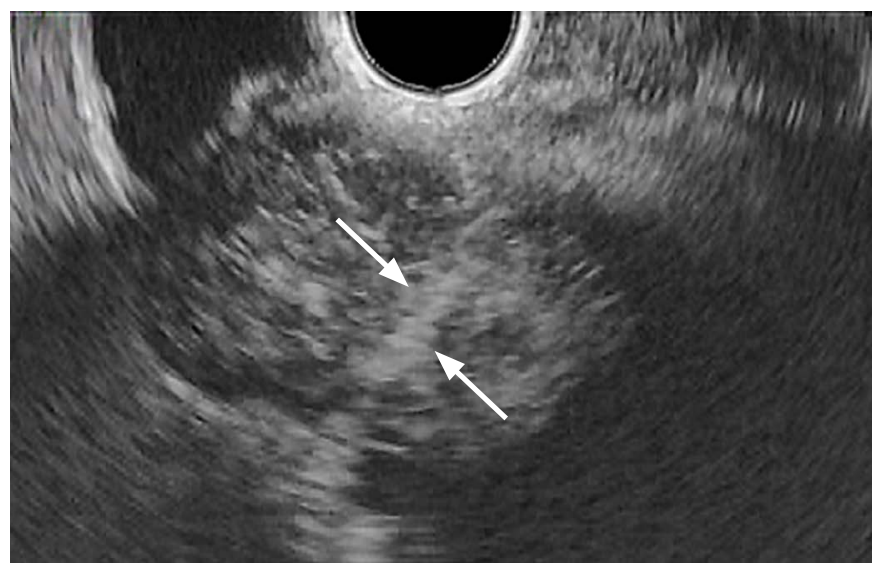

B
A

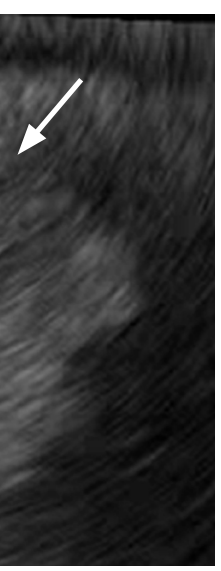

Fig. 6. A 75-year-old man with gallbladder carcinoma.

A. Fundamental B-mode endoscopic ultrasonography (EUS) demonstrates a solid tumor in the gallbladder (arrows). B. Contrast-enhanced harmonic EUS shows heterogeneous enhancement and irregular vessels (arrows) in the lesion. 
Red is used for encoding soft tissue, blue for hard tissue, and yellow/ green for tissue of intermediate stiffness (Fig. 7). Several different variables have been used in EUS-E as a measure of tissue elasticity, color patterns and strain ratio (SR), using analytical techniques such as hue-histogram analysis, and artificial neural networks [5255]. The classification of color patterns, which is qualitative, may be limited by its subjectivity, which could lead to differences in interpretation between endosonographers. This is less likely to be a significant problem for the remaining three quantitative variables, which are supplementary to the qualitative variable.

\section{Diagnosis of Malignant Pancreatic Lesions}

The primary aim of EUS-E is to distinguish benign and malignant tumors through the assessment of tissue elasticity (with benign tumors being soft while malignant tumors are hard) [56]. The first clinical experience with the qualitative analysis of EUS-E was obtained in 49 patients in 2006, and the authors of that study observed an optimal sensitivity (100\%) for both pancreatic malignancies and malignant lymph nodes [52]. Iglesias-Garcia et al. [57] extended this type of analysis by using the following four patterns: homogeneous green, heterogeneous green-predominant, homogeneous blue, and heterogeneous blue-predominant. They found that this method diagnosed pancreatic malignancies with a sensitivity, specificity, and overall accuracy of $100 \%, 85.5 \%$, and
$94 \%$, respectively. Two studies have assessed the accuracy of SRbased EUS-E for diagnosing pancreatic malignancies, with the sensitivity ranging from $93 \%$ to $100 \%$ and the specificity ranging from $17 \%$ to $95 \%[54,58]$. Therefore, SR-based EUS-E results are problematically variable, especially with regard to specificity. In 2012-2013, six meta-analyses have been published on this subject. Pei et al. [59] identified 1,042 patients with solid pancreatic masses and found that EUS-E showed a pooled sensitivity and specificity of $95 \%(93 \%-96 \%)$ and $69 \%(63 \%-75 \%)$, respectively, with an area under the ROC curve (AUC) of 0.870 for the differential diagnosis of benign and malignant masses. Mei et al. [60] reported similar data in 1,044 cases: for EUS-E, the pooled sensitivity was $95 \%(94 \%$ $97 \%)$, the pooled specificity was $67 \%(61 \%-73 \%)$, the diagnostic odds ratio was 42.28 (26.90-66.46), and the AUC was 0.905 .

\section{Diagnosis of Chronic Pancreatitis}

EUS-E is also used for the diagnosis of chronic pancreatitis (CP). Janssen and Papavassiliou [61] compared pancreatic elasticity among healthy patients younger than 60 years of age (group 1) and older than 60 years of age (group 2) with patients with CP (group 3). Histogram analysis of the elastograms (with 0 corresponding to the hardest tissue and 255 indicating the softest tissue) showed that the mean strain values were $110.2 \pm 23.9,80.0 \pm 16.4$, and $32.4 \pm 11.9$ in groups 1,2, and 3, respectively. They identified a cut-off value of

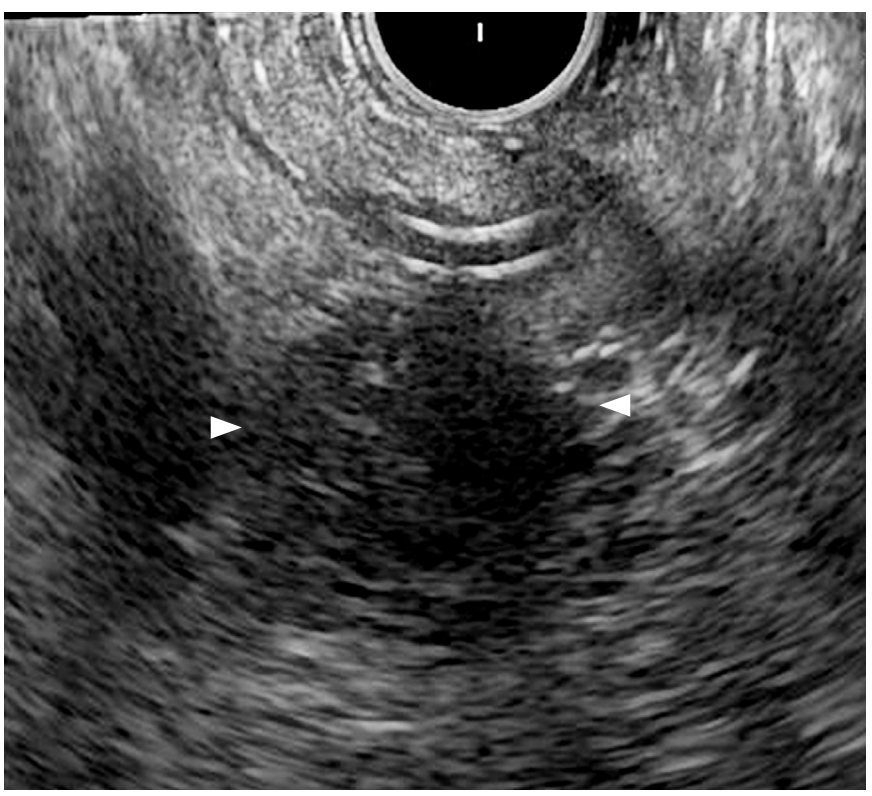

A

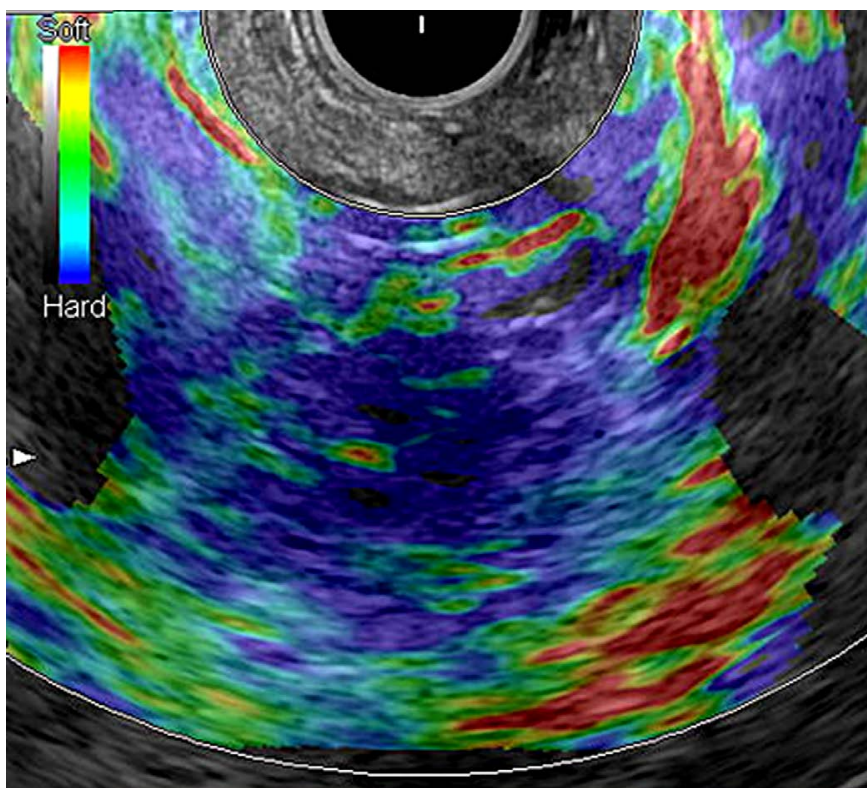

B

Fig. 7. A 68-year-old man with pancreatic ductal adenocarcinoma.

A. Fundamental B-mode endoscopic ultrasonography (EUS) demonstrates a hypoechoic mass (arrowheads) in the head of the pancreas. B. EUS elastography shows a relatively homogenous hard pattern (predominantly blue) at the site of the tumor in comparison to the surrounding tissues. 
50 that was able to distinguish the presence of $\mathrm{CP}$ in contrast to healthy people older than 60 years of age with an AUC of 0.993 . These results show that the pancreatic parenchyma becomes significantly harder during aging but remains softer than in patients with CP. Itoh et al. [62] evaluated the ability of EUS-E to quantify the degree of fibrosis of the parenchyma surrounding pancreatic tumors in 58 patients undergoing pancreasectomy. On average, EUS-E (performed through software analysis) showed an AUC of 0.90 for the diagnosis of pancreatic fibrosis. Recently, Dominguez-Munoz et al. [63] enrolled 115 patients with CP undergoing EUS in order to evaluate the correlation between EUS-E and pancreatic exocrine insufficiency (PEI). They observed that pancreatic fibrosis was directly correlated with PEl; in particular, patients with PEI ( $30 \%$ of the study population) showed a significantly higher $S R$ than patients with $C P$ with no PEI (4.89 vs. $2.99, P<0.001$ ). They also estimated that the probability of PEI was $<5 \%$ in patients with a SR $<2.5$ and $>90 \%$ in patients with a $S R>5.5$.

\section{Biliary Tree and Gallbladder Diseases}

Few reports have yet evaluated EUS-E of the biliary tree and gallbladder. Since the common bile duct is a hollow organ, the application of EUS-E may be limited when the bile duct is not completely blocked and the mass does not infiltrate beyond the wall. Rustemovic et al. [64] evaluated EUS-E as a method for screening patients with suspected primary sclerosing cholangitis. They found that a hard or mixed elasticity score was observed more frequently in patients with primary sclerosing cholangitis $(\mathrm{P}<0.001)$. According to a recent review article, EUS-E can demonstrate a homogeneously hard (blue) elastographic pattern in malignant masses that infiltrate the bile duct and extend beyond the wall, causing stenosis [65].

\section{Conclusion}

Technological innovations such as EUS-FNA, CH-EUS, and EUS-E have improved the ability of EUS to detect and characterize pancreaticobiliary lesions. These methods supplement the diagnostic use of conventional EUS.

ORCID: Ken Kamata: http://orcid.org/0000-0003-1568-0769; Masayuki Kitano: http://orcid.org/0000-0001-6885-9223; Shunsuke Omoto: http://orcid.org/00000001-7291-3608; Kumpei Kadosaka: http://orcid.org/0000-0003-3993-1673; Takeshi Miyata: http://orcid.org/0000-0003-4702-2197; Kosuke Minaga: http://orcid.org/00000001-5407-7925; Kentaro Yamao: http://orcid.org/0000-0003-2497-7740; Hajime Imai: http://orcid.org/0000-0001-6767-7989; Masatoshi Kudo: http://orcid.org/00000002-4102-3474

\section{Conflict of Interest}

No potential conflict of interest relevant to this article was reported.

\section{Supplementary Material}

Video clip 1. In the same patient presented in Fig. 2, the pancreatic cancer shows a gradual hyperenhancement during contrastenhanced harmonic endoscopic ultrasonography (http://dx.doi. org/10.14366/usg.15042.v001).

Video clip 2. In the same patient presented in Fig. 5, contrastenhanced harmonic EUS shows the vascularity of the true mural nodule, as distinguished from non-enhancing mucus clots in the cystic lesion (http://dx.doi.org/10.14366/usg.15042.v002).

\section{References}

1. Rosch T, Lorenz R, Braig C, Feuerbach S, Siewert JR, Schusdziarra $V$, et al. Endoscopic ultrasound in pancreatic tumor diagnosis. Gastrointest Endosc 1991;37:347-352.

2. Yasuda K, Mukai H, Nakajima M, Kawai K. Staging of pancreatic carcinoma by endoscopic ultrasonography. Endoscopy 1993;25: 151-155.

3. Gress FG, Hawes RH, Savides TJ, Ikenberry SO, Cummings 0 , Kopecky K, et al. Role of EUS in the preoperative staging of pancreatic cancer: a large single-center experience. Gastrointest Endosc 1999;50:786-791.

4. DeWitt J, Devereaux B, Chriswell M, McGreevy K, Howard T, Imperiale TF, et al. Comparison of endoscopic ultrasonography and multidetector computed tomography for detecting and staging pancreatic cancer. Ann Intern Med 2004;141:753-763.

5. Sakamoto H, Kitano M, Suetomi Y, Maekawa K, Takeyama Y, Kudo M. Utility of contrast-enhanced endoscopic ultrasonography for diagnosis of small pancreatic carcinomas. Ultrasound Med Biol 2008;34:525-532.

6. Fusaroli P, Spada A, Mancino MG, Caletti G. Contrast harmonic echo-endoscopic ultrasound improves accuracy in diagnosis of solid pancreatic masses. Clin Gastroenterol Hepatol 2010;8:629-634.

7. Dumonceau JM, Polkowski M, Larghi A, Vilmann P, Giovannini $M$, Frossard JL, et al. Indications, results, and clinical impact of endoscopic ultrasound (EUS)-guided sampling in gastroenterology: European Society of Gastrointestinal Endoscopy (ESGE) Clinical Guideline. Endoscopy 2011;43:897-912.

8. Hewitt MJ, McPhail MJ, Possamai L, Dhar A, Vlavianos P, Monahan KJ. EUS-guided FNA for diagnosis of solid pancreatic neoplasms: a meta-analysis. Gastrointest Endosc 2012;75:319-331.

9. Itoi T, Sofuni A, Itokawa F, Irisawa A, Khor CJ, Rerknimitr R. Current status of diagnostic endoscopic ultrasonography in the evaluation of pancreatic mass lesions. Dig Endosc 2011;23 Suppl 1:17-21.

10. Chen G, Liu S, Zhao Y, Dai M, Zhang T. Diagnostic accuracy of endoscopic ultrasound-guided fine-needle aspiration for pancreatic cancer: a meta-analysis. Pancreatology 2013;13:298-304.

11. Puli SR, Bechtold ML, Buxbaum JL, Eloubeidi MA. How good is 
endoscopic ultrasound-guided fine-needle aspiration in diagnosing the correct etiology for a solid pancreatic mass?: a meta-analysis and systematic review. Pancreas 2013;42:20-26.

12. Siddiqui UD, Rossi F, Rosenthal LS, Padda MS, Murali-Dharan V, Aslanian HR. EUS-guided FNA of solid pancreatic masses: a prospective, randomized trial comparing 22-gauge and 25-gauge needles. Gastrointest Endosc 2009;70:1093-1097.

13. Yusuf TE, Ho S, Pavey DA, Michael H, Gress FG. Retrospective analysis of the utility of endoscopic ultrasound-guided fine-needle aspiration (EUS-FNA) in pancreatic masses, using a 22-gauge or 25-gauge needle system: a multicenter experience. Endoscopy 2009;41:445-448.

14. Lee JH, Stewart J, Ross WA, Anandasabapathy S, Xiao L, Staerkel G. Blinded prospective comparison of the performance of 22-gauge and 25-gauge needles in endoscopic ultrasound-guided fine needle aspiration of the pancreas and peri-pancreatic lesions. Dig Dis Sci 2009:54:2274-2281.

15. Rastogi A, Wani S, Gupta N, Singh V, Gaddam S, Reddymasu S, et al. A prospective, single-blind, randomized, controlled trial of EUS-guided FNA with and without a stylet. Gastrointest Endosc 2011;74:58-64.

16. Madhoun MF, Wani SB, Rastogi A, Early D, Gaddam S, Tierney WM, et al. The diagnostic accuracy of 22-gauge and 25-gauge needles in endoscopic ultrasound-guided fine needle aspiration of solid pancreatic lesions: a meta-analysis. Endoscopy 2013;45:86-92.

17. Iglesias-Garcia J, Poley JW, Larghi A, Giovannini M, Petrone MC, Abdulkader I, et al. Feasibility and yield of a new EUS histology needle: results from a multicenter, pooled, cohort study. Gastrointest Endosc 2011;73:1189-1196.

18. Larghi A, Iglesias-Garcia J, Poley JW, Monges G, Petrone MC, Rindi G, et al. Feasibility and yield of a novel 22-gauge histology EUS needle in patients with pancreatic masses: a multicenter prospective cohort study. Surg Endosc 2013;27:3733-3738.

19. Hucl T, Wee E, Anuradha S, Gupta R, Ramchandani M, Rakesh $K$, et al. Feasibility and efficiency of a new $22 \mathrm{G}$ core needle: a prospective comparison study. Endoscopy 2013;45:792-798.

20. Bang JY, Hebert-Magee S, Trevino J, Ramesh J, Varadarajulu S. Randomized trial comparing the 22-gauge aspiration and 22-gauge biopsy needles for EUS-guided sampling of solid pancreatic mass lesions. Gastrointest Endosc 2012;76:321-327.

21. Iwashita T, Nakai Y, Samarasena JB, Park DH, Zhang Z, Gu M, et al. High single-pass diagnostic yield of a new 25-gauge core biopsy needle for EUS-guided FNA biopsy in solid pancreatic lesions. Gastrointest Endosc 2013;77:909-915.

22. Lee YN, Moon JH, Kim HK, Choi HJ, Choi MH, Kim DC, et al. Core biopsy needle versus standard aspiration needle for endoscopic ultrasound-guided sampling of solid pancreatic masses: a randomized parallel-group study. Endoscopy 2014;46:1056-1062.

23. Bang JY, Magee SH, Ramesh J, Trevino JM, Varadarajulu S.
Randomized trial comparing fanning with standard technique for endoscopic ultrasound-guided fine-needle aspiration of solid pancreatic mass lesions. Endoscopy 2013:45:445-450.

24. Brugge WR, Lewandrowski $K$, Lee-Lewandrowski $E$, Centeno BA, Szydlo T, Regan S, et al. Diagnosis of pancreatic cystic neoplasms: a report of the cooperative pancreatic cyst study. Gastroenterology 2004;126:1330-1336.

25. van der Waaij LA, van Dullemen HM, Porte RJ. Cyst fluid analysis in the differential diagnosis of pancreatic cystic lesions: a pooled analysis. Gastrointest Endosc 2005;62:383-389.

26. Varadarajulu S, Eloubeidi MA. Frequency and significance of acute intracystic hemorrhage during EUS-FNA of cystic lesions of the pancreas. Gastrointest Endosc 2004;60:631-635.

27. O'Toole D, Palazzo L, Arotcarena R, Dancour A, Aubert A, Hammel $P$, et al. Assessment of complications of EUS-guided fine-needle aspiration. Gastrointest Endosc 2001;53:470-474.

28. Williams DB, Sahai AV, Aabakken L, Penman ID, van Velse A, Webb J, et al. Endoscopic ultrasound guided fine needle aspiration biopsy: a large single centre experience. Gut 1999;44:720-726.

29. Walsh RM, Zuccaro G, Dumot JA, Vargo J, Biscotti CV, Hammel J, et al. Predicting success of endoscopic aspiration for suspected pancreatic cystic neoplasms. JOP 2008;9:612-617.

30. Konda VJ, Meining A, Jamil LH, Giovannini M, Hwang JH, Wallace $M B$, et al. A pilot study of in vivo identification of pancreatic cystic neoplasms with needle-based confocal laser endomicroscopy under endosonographic guidance. Endoscopy 2013;45:1006-1013.

31. Nakai Y, Iwashita T, Park DH, Samarasena JB, Lee JG, Chang KJ. Diagnosis of pancreatic cysts: EUS-guided, through-the-needle confocal laser-induced endomicroscopy and cystoscopy trial: DETECT study. Gastrointest Endosc 2015;81:1204-1214.

32. Jacobson BC, Pitman MB, Brugge WR. EUS-guided FNA for the diagnosis of gallbladder masses. Gastrointest Endosc 2003;57:251254.

33. Meara RS, Jhala D, Eloubeidi MA, Eltoum I, Chhieng DC, Crowe DR, et al. Endoscopic ultrasound-guided FNA biopsy of bile duct and gallbladder: analysis of 53 cases. Cytopathology 2006;17:42-49.

34. Hijioka S, Hara K, Mizuno N, Imaoka H, Ogura T, Haba S, et al. Diagnostic yield of endoscopic retrograde cholangiography and of EUS-guided fine needle aspiration sampling in gallbladder carcinomas. J Hepatobiliary Pancreat Sci 2012;19:650-655.

35. Varadarajulu S, Eloubeidi MA. Endoscopic ultrasound-guided fine-needle aspiration in the evaluation of gallbladder masses. Endoscopy 2005;37:751-754.

36. Dietrich CF, Ignee A, Frey H. Contrast-enhanced endoscopic ultrasound with low mechanical index: a new technique. Z Gastroenterol 2005;43:1219-1223.

37. Kitano M, Sakamoto H, Matsui U, Ito Y, Maekawa K, von Schrenck $T$, et al. A novel perfusion imaging technique of the pancreas: contrast-enhanced harmonic EUS (with video). Gastrointest Endosc 
2008;67:141-150.

38. Kitano M, Kudo M, Yamao K, Takagi T, Sakamoto H, Komaki T, et al. Characterization of small solid tumors in the pancreas: the value of contrast-enhanced harmonic endoscopic ultrasonography. Am J Gastroenterol 2012;107:303-310.

39. Napoleon B, Alvarez-Sanchez MV, Gincoul R, Pujol B, Lefort C, Lepilliez V, et al. Contrast-enhanced harmonic endoscopic ultrasound in solid lesions of the pancreas: results of a pilot study. Endoscopy 2010;42:564-570.

40. Gincul R, Palazzo M, Pujol B, Tubach F, Palazzo L, Lefort C, et al. Contrast-harmonic endoscopic ultrasound for the diagnosis of pancreatic adenocarcinoma: a prospective multicenter trial. Endoscopy 2014;46:373-379.

41. Gong TT, Hu DM, Zhu Q. Contrast-enhanced EUS for differential diagnosis of pancreatic mass lesions: a meta-analysis. Gastrointest Endosc 2012;76:301-309.

42. Koito K, Namieno T, Nagakawa T, Shyonai T, Hirokawa N, Morita K. Solitary cystic tumor of the pancreas: EUS-pathologic correlation. Gastrointest Endosc 1997;45:268-276.

43. Kubo H, Nakamura K, Itaba S, Yoshinaga S, Kinukawa N, Sadamoto $Y$, et al. Differential diagnosis of cystic tumors of the pancreas by endoscopic ultrasonography. Endoscopy 2009;41:684-689.

44. Ohno E, Hirooka Y, Itoh A, Ishigami M, Katano Y, Ohmiya N, et al. Intraductal papillary mucinous neoplasms of the pancreas: differentiation of malignant and benign tumors by endoscopic ultrasound findings of mural nodules. Ann Surg 2009;249:628-634.

45. Kurihara N, Kawamoto H, Kobayashi Y, Okamoto Y, Yamamoto $\mathrm{N}$, Tsutsumi $\mathrm{K}$, et al. Vascular patterns in nodules of intraductal papillary mucinous neoplasms depicted under contrast-enhanced ultrasonography are helpful for evaluating malignant potential. Eur J Radiol 2012;81:66-70.

46. Hirooka Y, Naitoh Y, Goto H, Ito A, Hayakawa S, Watanabe $Y$, et al. Contrast-enhanced endoscopic ultrasonography in gallbladder diseases. Gastrointest Endosc 1998;48:406-410.

47. Imazu H, Mori N, Kanazawa K, Chiba M, Toyoizumi H, Torisu Y, et al. Contrast-enhanced harmonic endoscopic ultrasonography in the differential diagnosis of gallbladder wall thickening. Dig Dis Sci 2014;59:1909-1916.

48. Choi JH, Seo DW, Park DH, Lee SS, Lee SK, Kim MH. Utility of contrast-enhanced harmonic EUS in the diagnosis of malignant gallbladder polyps (with videos). Gastrointest Endosc 2013;78:484493.

49. Park CH, Chung MJ, Oh TG, Park JY, Bang S, Park SW, et al. Differential diagnosis between gallbladder adenomas and cholesterol polyps on contrast-enhanced harmonic endoscopic ultrasonography. Surg Endosc 2013;27:1414-1421.

50. Gao L, Parker KJ, Lerner RM, Levinson SF. Imaging of the elastic properties of tissue: a review. Ultrasound Med Biol 1996;22:959977.
51. Saftoiu A, Vilman P. Endoscopic ultrasound elastography: a new imaging technique for the visualization of tissue elasticity distribution. J Gastrointestin Liver Dis 2006;15:161-165.

52. Giovannini M, Hookey LC, Bories E, Pesenti C, Monges G, Delpero $J R$. Endoscopic ultrasound elastography: the first step towards virtual biopsy?: preliminary results in 49 patients. Endoscopy 2006;38:344-348.

53. Janssen J, Schlorer E, Greiner L. EUS elastography of the pancreas: feasibility and pattern description of the normal pancreas, chronic pancreatitis, and focal pancreatic lesions. Gastrointest Endosc 2007;65:971-978.

54. Dawwas MF, Taha H, Leeds JS, Nayar MK, Oppong KW. Diagnostic accuracy of quantitative EUS elastography for discriminating malignant from benign solid pancreatic masses: a prospective, single-center study. Gastrointest Endosc 2012;76:953-961.

55. Saftoiu A, Vilmann P, Gorunescu F, Janssen J, Hocke M, Larsen M, et al. Accuracy of endoscopic ultrasound elastography used for differential diagnosis of focal pancreatic masses: a multicenter study. Endoscopy 2011;43:596-603.

56. Fusaroli P, Saftoiu A, Mancino MG, Caletti G, Eloubeidi MA. Techniques of image enhancement in EUS (with videos). Gastrointest Endosc 2011;74:645-655.

57. Iglesias-Garcia J, Larino-Noia J, Abdulkader I, Forteza J, DominguezMunoz JE. EUS elastography for the characterization of solid pancreatic masses. Gastrointest Endosc 2009;70:1101-1108.

58. Saftoiu A, Iordache SA, Gheonea DI, Popescu C, Malos A, Gorunescu $F$, et al. Combined contrast-enhanced power Doppler and real-time sonoelastography performed during EUS, used in the differential diagnosis of focal pancreatic masses (with videos). Gastrointest Endosc 2010;72:739-747.

59. Pei Q, Zou X, Zhang X, Chen M, Guo Y, Luo H. Diagnostic value of EUS elastography in differentiation of benign and malignant solid pancreatic masses: a meta-analysis. Pancreatology 2012;12:402408.

60. Mei M, Ni J, Liu D, Jin P, Sun L. EUS elastography for diagnosis of solid pancreatic masses: a meta-analysis. Gastrointest Endosc 2013; 77:578-589.

61. Janssen J, Papavassiliou I. Effect of aging and diffuse chronic pancreatitis on pancreas elasticity evaluated using semiquantitative EUS elastography. Ultraschall Med 2014;35:253-258.

62. Itoh Y, Itoh A, Kawashima H, Ohno E, Nakamura Y, Hiramatsu $T$, et al. Quantitative analysis of diagnosing pancreatic fibrosis using EUS-elastography (comparison with surgical specimens). J Gastroenterol 2014;49:1183-1192.

63. Dominguez-Munoz JE, Iglesias-Garcia J, Castineira Alvarino M, Luaces Regueira M, Larino-Noia J. EUS elastography to predict pancreatic exocrine insufficiency in patients with chronic pancreatitis. Gastrointest Endosc 2015;81:136-142.

64. Rustemovic N, Cukovic-Cavka S, Opacic M, Petrovecki M, Hrstic I, 
Radic D, et al. Endoscopic ultrasound elastography as a method for screening the patients with suspected primary sclerosing cholangitis. Eur J Gastroenterol Hepatol 2010;22:748-753.
65. Cui XW, Ignee A, Braden B, Woenckhaus M, Dietrich CF. Biliary papillomatosis and new ultrasound imaging modalities. $Z$ Gastroenterol 2012;50:226-231. 